Original

\title{
Lethal photosensitization in microbiological treatment of ligature-induced peri-implantitis: a preliminary study in dogs
}

\author{
Jamil Awad Shibli ${ }^{\S}$, Marilia Compagnoni Martins ${ }^{\S}$, \\ Letícia Helena Theodoro ${ }^{\S}$, Roberto Fraga Moreira Lotufo ${ }^{\dagger}$, \\ Valdir Gouveia Garcia ${ }^{\ddagger}$ and Elcio Marcantonio Jr ${ }^{\S}$

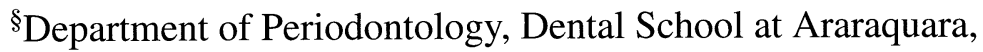 \\ State University of São Paulo (UNESP), Araraquara, SP, Brazil \\ ${ }^{\dagger}$ Department of Periodontology, Dental School of São Paulo, \\ University of São Paulo State (USP), São Paulo, SP, Brazil \\ ‡Department of Periodontology, Dental School at Araçatuba, \\ State University of São Paulo (UNESP), Araçatuba, SP, Brazil
}

(Received 9 January 2002 and accepted 22 January 2003)

\begin{abstract}
This pilot study evaluated, by culture testing, the effectiveness of lethal photosensitization for the microbiological treatment of peri-implantitis in dogs. Experimental peri-implantitis was induced by ligature placement for 2 months. Following ligature removal, plaque control was instituted by scrubbing with $0.12 \%$ chlorhexidine daily for 12 months. Subsequently, mucoperiosteal flaps were elevated for scaling the implant surface. Microbial samples were obtained with paper points before and after treatment of implant surfaces by means of $100 \mu \mathrm{g} / \mathrm{ml}$ toluidine blue $\mathrm{O}$ (TBO,) and were exposed, for $80 \mathrm{~s}$, to light with a wavelength of $685 \mathrm{~nm}$ from a $50 \mathrm{~mW}$ GaAlAs diode laser. The mean initial and final bacterial counts were $7.22 \pm 0.20$ and $6.84 \pm 0.44 \mathrm{CFU} / \mathrm{ml}$, respectively for TVC $(P<0.0001) ; 6.19 \pm 0.45$ and 3.14 $\pm 3.29 \mathrm{CFU} / \mathrm{ml}$ for $P$. intermedia/nigrescens $(P=0.001) ; 5.98 \pm 0.38$ and $1.69 \pm 2.90 \mathrm{CFU} / \mathrm{ml}$ for Fusobacterium spp. $(P=0.001)$; and $6.07 \pm 0.22$ to $1.69 \pm 2.94 \mathrm{CFU} / \mathrm{ml}$ for beta-hemolytic Streptococcus $(P=0.0039)$. It may be concluded that lethal photosensitization resulted in a reduction of the
\end{abstract}

Correspondence to Dr. Elcio Marcantonio Jr, Periodontia Faculdade de Odontologia de Araraquara, UNESP, R. Humaitá, 1680, Araraquara, SP, 14801-903, Brazil

Tel.: +55162016369

Fax: +55162016314

E-mail: elciojr@foar.unesp.br bacterial count. Complete elimination of bacteria was achieved in some samples. (J. Oral Sci. 45, 17-23, 2003)

Key words: Dental implants; laser therapy; osseointegration; periodontal pathogens; peri-implantitis; photodynamic antimicrobial chemotherapy.

\section{Introduction}

Early studies have documented the excellent long-term prognosis of osseointegration (1). However, several different etiologic factors are associated with dental implant failures, such as poor surgical management, failure to achieve osseointegration, premature loading, biomechanical overload (2), and main peri-implant infection, due to colonization by bacteria such as Actinobacillus actinomycetemcomitans, Porphyromonas gingivalis, Prevotella intermedia, Fusobacterium nucleatum, and Bacteroides forsythus (3). Dental implant failure, or periimplantitis, is defined as an inflammatory process affecting the tissues around a in function dental implant, resulting in loss of supporting bone (4).

Several therapeutic strategies can be applied for the treatment of peri-implantitis (5-7). In some of these in vivo studies, clinical, radiographical and histological evaluations were performed without considering the microbiological 
features before and after contamination of the implant surface.

Discontamination by mechanical (7), chemical (5) and physical $(8,9)$ methods have been used.

The physical method, utilizing a low-power laser following the application of a photosensitizing substance, such as toluidine blue $\mathrm{O}$ (TBO) (10), has been used to treat periodontal diseases (11-14) and peri-implantitis $(8,9)$. The mechanism by which TBO plus laser irradiation kills microorganisms such as Porphyromonas gingivalis, Prevotella intermedia, Actinobacillus actinomycetemcomitans, and Fusobacterium nucleatum has not yet been established. However, it is believed that lethal photosensitization of these microorganisms may involve changes in their membranes and/or plasma membrane proteins, as well as DNA damage mediated by singlet oxygen (13).

The purpose of this study, therefore, was to evaluate, by culture testing, the viability of microorganisms, following lethal photosensitization, during the microbiological treatment of ligature-induced peri-implantitis in dogs.

\section{Materials and Methods \\ Animals and implants}

The outline of the experiment is presented in Fig. 1. A total of six consecutively treated mongrel dogs (24-months old with an average weight of $18 \mathrm{~kg}$ ) with ligature-induced peri-implantitis around 19 dental implants were treated in this study. Animal selection, management, and surgical protocol followed routines approved by the Dental School of Araraquara Institutional Animal Care and Use Committee.

All mandibular premolars were extracted to create space for dental implants. After three months of healing, 36 dental implants with four different surfaces and three different implant systems: commercially pure titanium implants-CP, $3 i^{\circledR}$ Implants Innovations, Palm Beach Gardens, FL, USA; titanium plasma sprayed-TPS, Esthetic

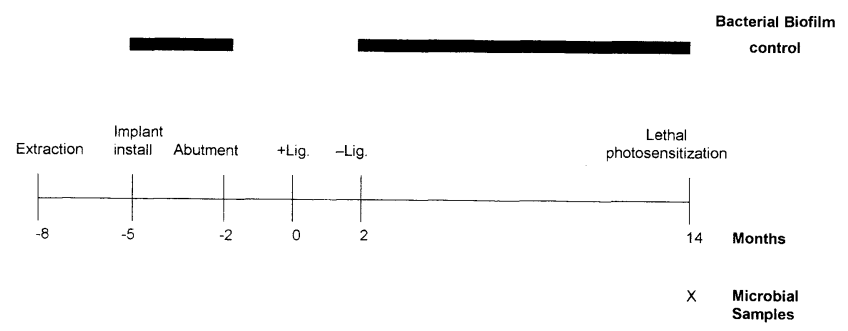

Fig. 1 Outline of the experiment. Ligatures were placed around the dental implants at 0 months (+Lig.) and removed at 2 months (-Lig.). Treatment of peri-implantitis was performed at 14 months by photodynamic therapy. plus ITI $^{\circledR}$, Straumann AG, Waldenburg, Switzerland; hydroxyapatite-HA, Calcitek ${ }^{\circledR}$, Sulzer Medica, Carlsbad, CA, USA; hybrid surface-machined titanium in the three screws and acid-etched-acid, Osseotite ${ }^{\circledR}-3 i^{\circledR}$ Implants Innovations, Palm Beach Gardens, FL, USA were installed in each quadrant of the mandible.

Three months after fixture installation, healing abutment connections were installed, according to the instructions of each dental implant system. After a plaque control program for two months and healing of the soft tissue, cotton floss ligatures were placed around the dental implants and sutured in the peri-implant mucosa, not only to facilitate plaque accumulation, but also to hold the ligatures in position. Tying further ligatures at 20 day-intervals for a period of 60 days accelerated peri-implant bone loss. At 60 days, when approximately $40 \%$ of the initial bone support was lost, the ligatures were finally removed.

A 12-month plaque control program was initiated by means of scrubbing daily with $0.12 \%$ chlorhexidine and scaling the abutment surface once a month. At the end of this period, natural peri-implantitis progression was observed, and only 19 dental implants (5 CP, 6 TPS, 3 HA, and 5 acid) remained osseointegrated.

\section{Treatment}

A crestal incision was made through the mucosa and buccal and lingual full-thickness flaps were elevated. The abutments were removed and the granulation tissue present in the bone craters around the dental implants was curetted with a plastic curette (Fig. 2). The implant surface was then rinsed with physiological saline solution and the first periimplant microbial sample was taken. TBO $(100(\mu / \mathrm{ml})$ was then injected into the peri-implant defect as far as the bony border with a thin needle; the TBO was left in place for 1 minute and then carefully drawn off again. The stained area was subsequently irradiated with a GaAlAs

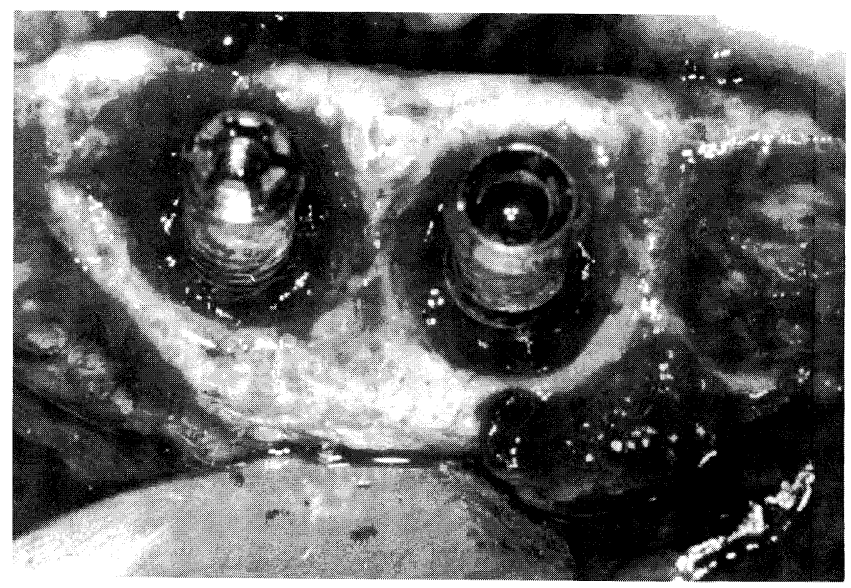

Fig. 2 Clinical view of peri-implant defects after debridment. 
diode laser (IR 500-Laser Beam, Brazil) with a measured power output of $50 \mathrm{~mW}$ (Fig. 3). This laser emits radiation in collimated beams $\left(2 \mathrm{~mm}^{2}\right)$ with a wavelength of $685 \mathrm{~nm}$, for $80 \mathrm{~s}$ and a total energy of $4 \mathrm{~J}$ (energy density, $200 \mathrm{~J} / \mathrm{cm}^{2}$ ). The diode laser was focalized in contact with the mesial, distal, buccal and lingual surfaces by a scanning method for $20 \mathrm{~s}$ on each face, making a total of $80 \mathrm{~s}$. The second microbial sample was then obtained.

\section{Microbial Samples}

The paper points were removed and placed into 3-ml vials containing VMGAIII anaerobic transport medium (15). All samples were collected by the same operator and coded by an assistant to provide blind identification. The microbiological procedures were initiated within 24 hours.

The samples were centrifuged for $60 \mathrm{~s}$ and were serially diluted 10-fold in peptonated water to between $10^{-1}$ and $10^{-6}$ for quantitative evaluation of $\mathrm{CFU} / \mathrm{ml}$ and to obtain isolated colonies for qualitative identification. Aliquots of $0.1 \mathrm{ml}$ of the dilutions were plated onto Enriched Tryptic Soy Agar (ETSA) (16) and Tryptic Soy-Serum-BacitracinVancomycin agar (TSBV) (17) in a standard manner. ETSA plates were incubated in anaerobic jars containing a mixed gas atmosphere $\left(85 \% \mathrm{~N}_{2}, 10 \% \mathrm{H}_{2}, 5 \% \mathrm{CO}_{2}\right)$ at $37^{\circ} \mathrm{C}$ for 7 to 10 days. TSBV agar plates were incubated in a $5 \% \mathrm{CO}_{2}$ atmosphere for 5 days at $37^{\circ} \mathrm{C}$. The bacterial species were identified from anaerobic cultures based on gram-stain, aerotolerance, colony morphology, esculin hydrolysis (18), nitrate reduction, indole production, [alpha]-glucosidase and N-benzoyl-DL-arginine-2naphthylamide (BANA) hydrolysis (19), oxidase and catalase activities. Total viable count (TVC) and cultivable microbiota, including Porphyromonas gingivalis, Prevotella intermedia/nigrescens, Fusobacterium spp., beta-hemolytic Streptococcus. Actinobacillus actinomycetemcomitans

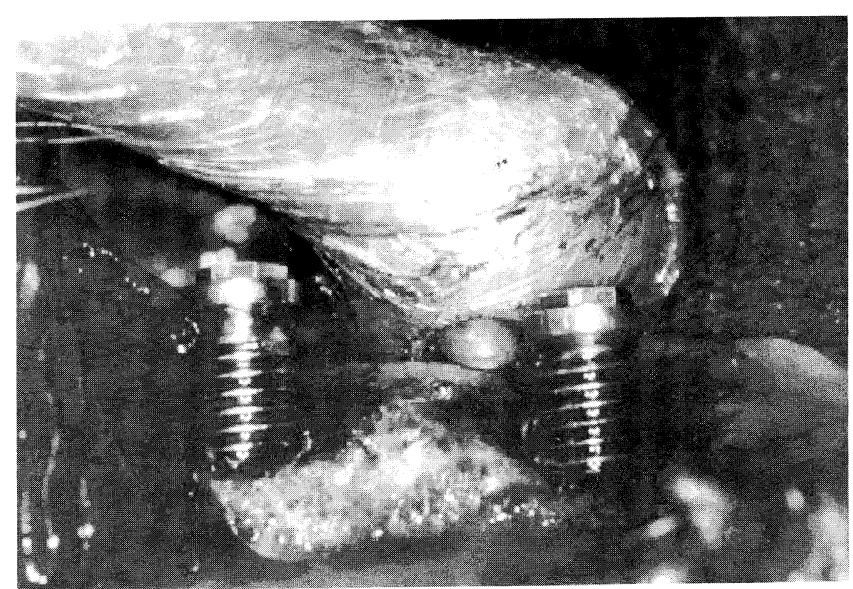

Fig. 3 Clinical view of peri-implant defect and dental implant surface after stained by TBO. detection was performed based on colony morphology and positive catalase tests (20).

\section{Data Analysis}

The TVC were transformed into colony-forming units per $\mathrm{ml}(\mathrm{CFU} / \mathrm{ml})$ using predetermined conversion factors to account for dilution and the size of the evaluated surface on the plate.

Data were then analyzed for each dental implant. Differences between groups and bacterial species were assessed by Wilcoxon's signed rank-test $(P<0.05)$. Microorganism analysis was performed after logarithmic transformation of TVC for each periodontal pathogen.

\section{Results}

P. gingivalis and A. actinomycetemcomitans were not detected in any peri-implant microbial sample.

The mean initial bacterial count ranged around 7.22 \pm $0.20 \mathrm{CFU} / \mathrm{ml}$ for TVC, $6.19 \pm 0.45 \mathrm{CFU} / \mathrm{ml}$ for $P$. intermedia/nigrescens, $5.98 \pm 0.38 \mathrm{CFU} / \mathrm{ml}$ for Fusobacterium spp., and $6.07 \pm 0.22 \mathrm{CFU} / \mathrm{ml}$ for betahemolytic Streptococcus.

The means measured following lethal photosensitization were even lower; $6.84 \pm 0.44 \mathrm{CFU} / \mathrm{ml}$ for TVC (Fig. 4), $3.14 \pm 3.29 \mathrm{CFU} / \mathrm{ml}$ for $P$. intermedia/nigrescens (Fig. 5), $1.69 \pm 2.90 \mathrm{CFU} / \mathrm{ml}$ for Fusobacterium spp. (Fig. 6), and $5.01 \pm 1.90 \mathrm{CFU} / \mathrm{ml}$ for beta-hemolytic Streptococcus (Fig. 7). Significant decreases in counts following lethal photosensitization were observed for TVC $(P<0.0001)$, $P$. intermedia/nigrescens $(P=0.001)$, Fusobacterium spp. $(P=0.001)$ and to beta-hemolytic Streptococcus $(P=$

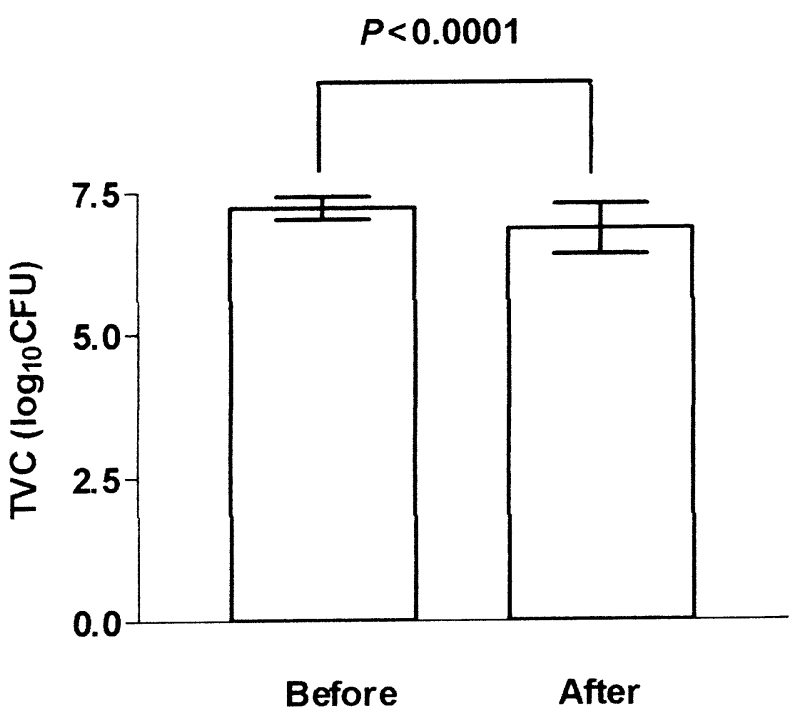

Fig. 4 Mean and standard deviation of the effect of lethal photosensitization on the viability of bacteria (TVC) in peri-implant microbial samples. 


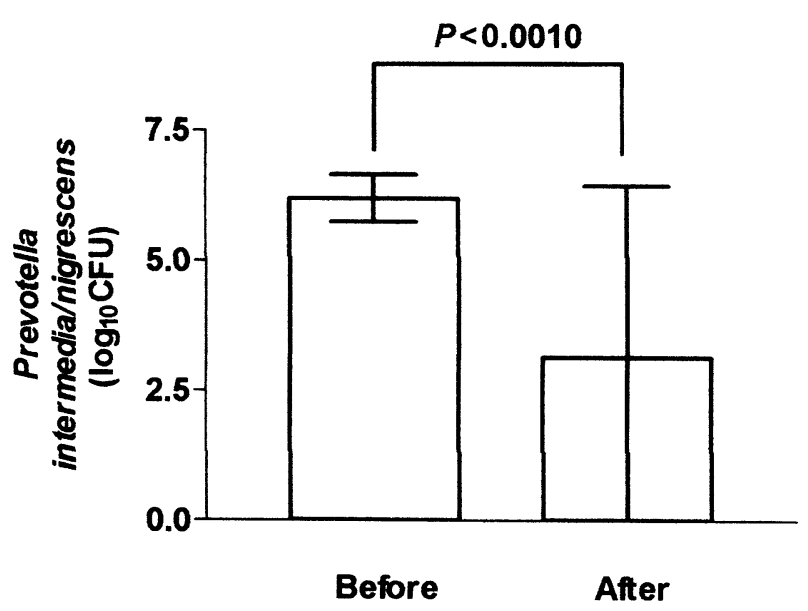

Fig. 5 Mean and standard deviation of the effect of lethal photosensitization on viability in all samples positive for Prevotella intermedia/nigrescens.

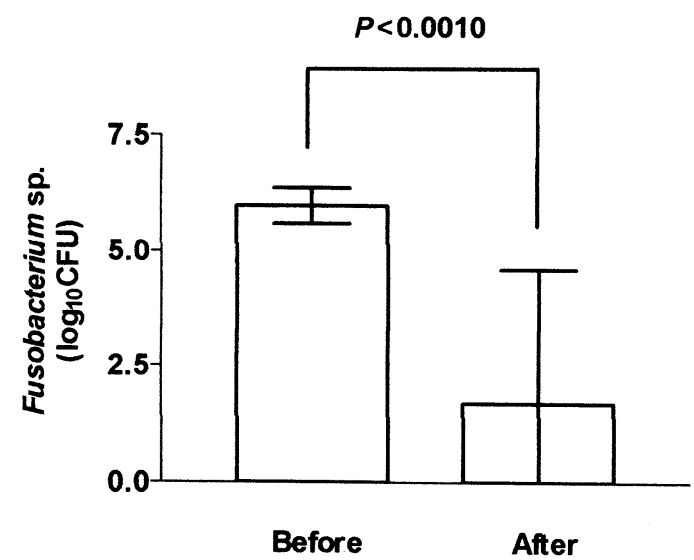

Fig. 6 Mean and standard deviation of the effect of lethal photosensitization on viability in all samples positive for Fusobacterium spp.

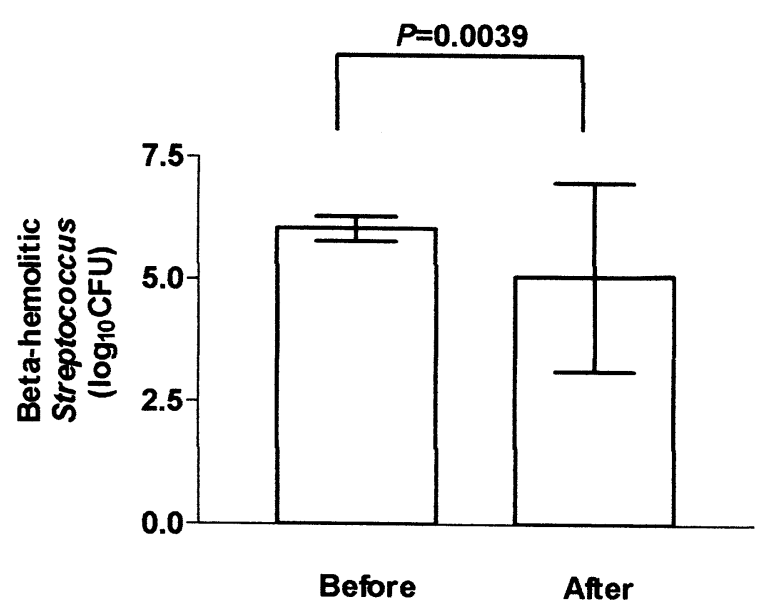

Fig. 7 Mean and standard deviation of the effect of lethal photosensitization on viability in all samples positive for beta-hemolytic Streptococcus.
0.0039).

Complete bacterial elimination was achieved in $P$. intermedia/nigrescens (6 out of 12 samples), Fusobacterium spp. (6 in 11 samples), and beta-hemolytic Streptococcus (1 in 9 samples) (Table 1).

\section{Discussion}

Several studies have demonstrated the bactericidal effect of high-power laser on contaminated dental implant surfaces (21-23). This energy is specifically absorbed by water molecules, which cause the water-rich tissue to be preferentially vaporized, in bacterial cytoplasm this effect causes cell lyses.

In addition, studies $(8,9,24)$ have shown the effectiveness of lethal photosensitization in decreasing the viable count of periodontal pathogens in peri-implantitis lesions without damage to the dental implant surface.

This preliminary study attempted to examine whether lethal photosensitization, which has been shown to be effective in eliminating periodontal pathogens (in vitro) on contaminated titanium implants surfaces (8), is also effective in vivo $(9,24)$. The results of this preliminary study indicate that photosensitization with TBO plus irradiation

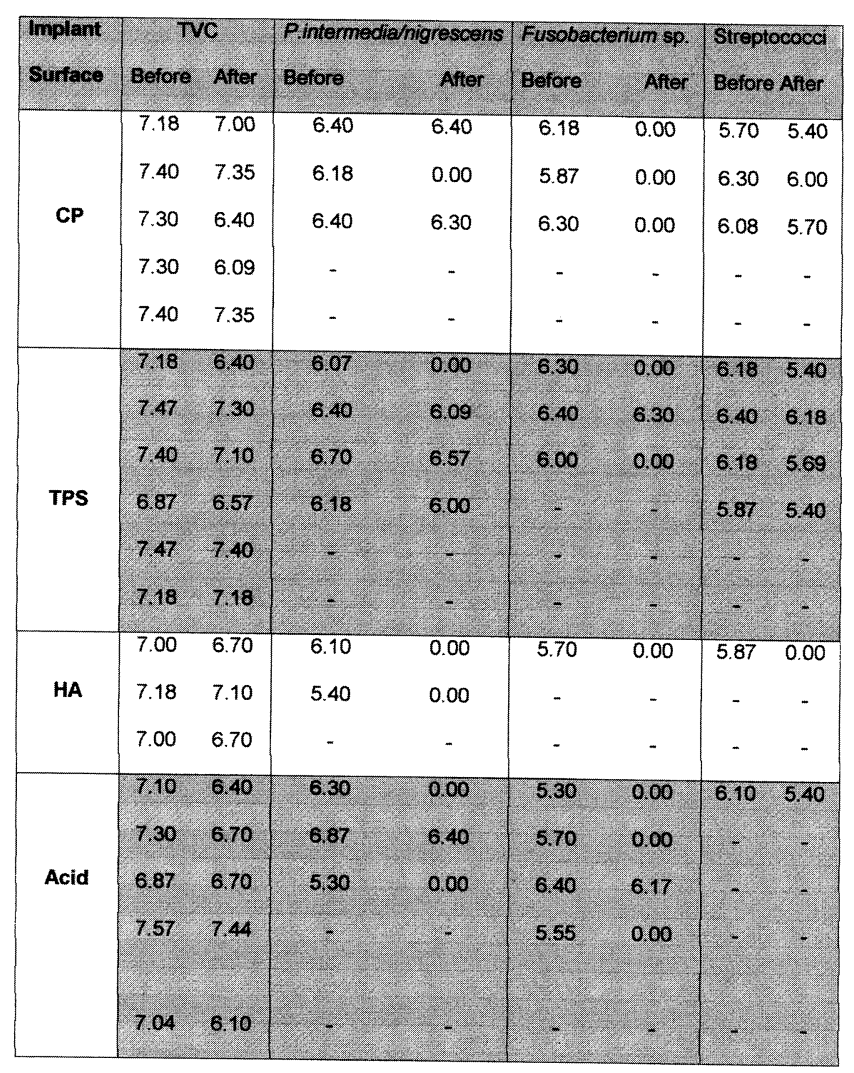

Table 1 CFU/ml after logarithmic transformation, before and after lethal photosensitization (-: Species were not identified in this site.) 
with a GaAlAs diode laser $\left(200 \mathrm{~J} / \mathrm{cm}^{2}\right)$ result in a statistical reduction of periodontal pathogens of up to a maximum of $1 \log$ step.

These results confirm those obtained by other studies that use various photosensitizers in combination with a lowpower laser to induce bacterial reduction $(25,26,27)$. Periodontal pathogens, such as Fusobacterium nucleatum, Prevotella intermedia and Actinobacillus actinomycetemcomitans were killed after photodynamic therapy (28). Furthermore, the dye/laser combination was demonstrated for the first time, to be able to reduce the beta-hemolytic Streptococcus mean count. However these data should be considered with caution due the sample size utilized in this pilot study and also due to absence of control group. In addition, other possibility that reduction of bacterial density in a fluid that filled the ligature-induced peri-implant defect can also caused by physical removal of the microorganisms prior to the second sample collection by stream of the TBO solution while staining and suctioning since it is well know that bacteria attach to the infragingival surfaces quite loosely.

Many factors may interfere in the laser irradiation, these include the capacity for light absorption by the microorganism, the wavelength of the laser, the physiological state of the bacteria, the emission form of the laser, the time of exposition to the laser, the $\mathrm{pH}$ of the medium, the staining of the area to be irradiated, water content, thermal conductivity and the organic matrix (29). In our study we could conclude that biofilm present on dental implants surfaces was susceptible to photodynamic treatment and their variables.

Various drugs have been used over the last few years in association with low-power lasers to promote their bactericidal effects, since the low-intensity lasers by themselves do not have the capacity to cause significant reductions in the microorganisms as they induce a photochemical reaction rather than a thermal reaction. However, the association of these lasers with photosensitizers causes an alteration in the viabilities of different microorganisms $(26,29,30)$, confirmed by our data. Several authors conclude that neither low intensity laser irradiation nor photosensitizers alone can kill these bacteria. Haas et al. (8) evaluated, by microbiologic examinations, the effectiveness of lethal photosensitization in different implant surfaces. They conclude that the group that utilized TBO plus laser was effective while the others groups (TBO alone, Laser alone, saline solution) were not effective. These results agree with the studies conducted by Bhatti et al. (31) and Bhatti et al. (8). In these works the authors evaluated not only the distribution of TBO but also the dosimetric effect and physiologic factors on lethal photosensitization of $P$. gingivalis. We can also cite Sarkar and Wilson (12), and Dortbudak et al. (9), who agree with the statement that lethal photosensitization is effective when the photosensitizer was used plus laser irradiation.

Although the mechanism by which the low-power lasers cause bacterial reduction when associated with photosensitizers is not totally clarified, some authors believe that when the laser is strongly absorbed locally, due to the sensitization of the bacterial photoreceptors by the stains, an oxygen molecule with a high degree of atomic excitation (oxygen triplet $=\mathrm{O}_{3}$ ) is produced, but only has a bactericidal effect upon the production of free radicals or singlet oxygen (29). The reason why an oxygen molecule affects only the bacteria is because the light dose required to kill bacteria treated with TBO is far lower than that causing toxicity in cultured human keratinocytes and fibroblasts (32). In addition to this important effect is the presence of the selectivity of the laser by the use of specific stains for each wavelength, due to the different degrees of absorption by the stains (33).

As well as being non-toxic to man, the ideal photosensitizer must be able to absorb strongly at the wavelength of light used, have high excitation efficiency (a high probability of triplet state formation per photon absorbed) and a relatively long (several microseconds) triplet state (29). Wilson et al. (33) screened a number of compounds for their ability to sensitize oral bacteria to killer by low power laser. These compounds include TBO, methylene blue, aluminum disulphonated phthalocyanine, thionin, crystal violet and dihaematoporphyrin ester (29).

This study utilized sensitization to TBO, since other studies $(25,31,34)$ have demonstrated the effectiveness of this stain in association with red spectrum-wavelength lasers on bacterial viability, probably due to the fact that TBO strongly absorbs visible spectrum wavelengths (red). This finding agrees with the theory that the bactericidal effect of lasers depends upon their wavelength (29). The wavelength used to kill periodontal pathogens in ligatureinduced peri-implantitis in this study was shown to be effective; however additional investigations must be conducted.

In addition, this approach to killing periodontal pathogens offers some advantages over the use of conventional antimicrobials: avoids development of resistance among target organisms to the photochemically-generated free radicals thought to be responsible for bacterial killing and, unlike antiseptics and antibiotics, there would be no need to maintain high concentrations of the TBO in the peri-implant defects for long periods.

Within the limits of this pilot study, it may be concluded that microbiological peri-implantitis treatment by lethal 
photosensitization reduced and eliminated, in some samples, the periodontal pathogens involved in this pathological condition. Further studies will be necessary to evaluate the amount of re-osseointegration after lethal photosensitization.

\section{Acknowledgments}

This study was supported by grants FAPESP 00/024331 and FAPESP 99/03026-1. The authors appreciate the collaboration of $3 i$ Implants Innovations-Brazil, for supplying part of dental implants.

\section{References}

1. Albrektsson T, Zarb G, Worthington R, Eriksson, AR (1986) The long-term efficacy of currently used dental implants: a review and proposed criteria of success. Int J Oral Maxillofac Implants 1, 11-25

2. Klokkevold PR, Newman MG (2000) Current status of dental implants: a periodontal perspective. Int J Oral Maxillofac Implants 15, 56-65

3. Mombelli A, Marxer M, Gaberthüel T, Grunder U, Lang NP (1995) The microbiota of osseointegrated implants in patients with a history of periodontal disease. J Clin Periodontol 22, 124-130

4. Mombelli A, Lang NP (1998) The diagnosis and treatment of peri-implantitis. Periodontol 2000 17, 63-76

5. Ericsson I, Persson LG, Berglundh T, Edlund T, Lindhe J (1996) The effect of antimicrobial therapy on periimplantitis lesions. An experimental study in the dog. Clin Oral Implants Res 7, 320-328

6. Hurzeler MB, Quinones CR, Morrison EC, Caffesse $\mathrm{R}$ (1995) Treatment of peri-implantitis using guided bone regeneration and bone grafts, alone or in combination, in beagle dogs. Part I: clinical findings and histologic observations. Int J Oral Maxillofac Implants 10, 474-484

7. Machado MAN, Stefani CM, Sallum EA, Sallum AW, Tramontina VA, Nociti Junior FH (1999) Treatment of ligature-induced peri-implantitis defects by regenerative procedures: a clinical study in dogs. J Oral Sci 41, 181-185

8. Haas R, Dörtbudak O, Mensdorff-Pouilly N, Mailath $G$ (1997) Elimination of bacteria on different implant surfaces through photosensitization and soft laser. An in vitro study. Clin Oral Implants Res 8, 249254

9. Dörtbudak O, Haas R, Bernhart T, Mailath-Pokorny, G (2001) Lethal photosensitization for decontamination of implant surfaces in the treatment of periimplantitis. Clin Oral Implants Res 12, 104-108
10. Wainwright M (1998) Photodynamic antimicrobial chemotherapy (PACT). J Antimicrob Chemother 42,13-28

11. Dobson J, Wilson M (1992) Sensitization of oral bacteria in biofilms to killing by light from a lowpower laser. Arch Oral Biol 37, 883-887

12. Sarkar S, Wilson M (1993) Lethal photosensitization of bacteria in subgingival plaque from patients with chronic periodontitis. J Periodont Res 28, 204-210

13. Bhatti M, MacRobert A, Meghji S, Henderson B, Wilson M (1998) A study of the uptake of toluidine blue $\mathrm{O}$ by Porphyromonas gingivalis and the mechanism of lethal photosensitization. Photochem Photobiol 68, 370-376

14. Bhatti M, MacRobert A, Henderson B, Shepherd P, Cridland J, Wilson M (2000) Antibody-targeted lethal photosensitization of Porphyromonas gingivalis. Antimicrob Agents Chemother 44, 26152618

15. Möller AJR (1966) Microbiological examination of root canals and periapical tissues of human teeth. Methodological studies. Odontol Tidskr 74, 1-380

16. Syed SA, Svanberg M, Svanberg G (1980) The predominant cultivable dental plaque flora of beagle dogs with gingivitis. J Periodontal Res15,123-136

17. Slots J (1982) Selective medium for isolation of Actinobacillus actinomycetemcomitans. J Clin Microbiol 15, 606-609

18. Qadri HSM, DeSilva MI, Zubairi S (1980) Rapid test for determination of esculin hydrolysis. J Clin Microbiol 12, 472-474

19. Laugthon BE, Syed SA, Loesche WJ (1982) Rapid identification of Bacteroides gingivalis. J Clin Microbiol15, 345-346

20. Slots J, Listgarten MA (1988) Bacteroides gingivalis, Bacteroides intermedius, and Actinobacillus actinomycetemcomitans in human periodontal diseases. J Clin Periodontol 15, 85-93

21. Kato T, Kusakari H, Hoshino E (1998) Bactericidal efficacy of carbon dioxide laser against bacteriacontaminated titanium implant and subsequent cellular adhesion to irradiated area. Lasers Surg Med 23, 299-309

22. Mouhyi J, Sennerby L, Nammour S, Guillaume P, Van Reck J (1999) Temperature increase during surface decontamination of titanium implants using $\mathrm{CO}_{2}$ laser. Clin Oral Implants Res 10, 54-61

23. Mouhyi J, Sennerby L, van Reck J (2000) The soft tissue response to contaminated and cleaned titanium surfaces using $\mathrm{CO}_{2}$ laser, citric acid and hydrogen peroxide. An experimental study in the rat abdominal 
wall. Clin Oral Implants Res 11, 93-98

24. Hass R, Baron M, Dortbudak O, Watzek G (2000) Lethal photosensitization, autogenous bone, and ePTFE membrane for the treatment of peri-implantitis: preliminary results. Int J Oral Maxillofac Implants $15,374-382$

25. Burns T, Wilson M, Pearson G (1993) Sensitiztion of cariogenic bacteria to killing by light from helionneon laser. J Med Microbiol 38, 401-405

26. Burns T, Wilson M, Pearson GJ (1994) Killing of cariogenic bacteria by light from a gallium aluminium arsenide diode laser. J Dent 22, 27327825.

27. Wilson M, Burns T, Pratten J, Pearson GJ (1995) Bacteria in supragingival plaque samples can be killed by low-power laser light in the presence of a photosensitizer. J Appl Bacteriol 78, 569-574

28. Wilson M, Dobson J, Sarkar S (1993) Sensitization of periodonto-pathogenic bacteria to killing by light from a low-power laser. Oral Microbiol Immunol 8, 182-187

29. Wilson M (1994) Bactericidal effect of laser light and its potencial use in the treatment of plaquerelated diseases. Int Dent J 44, 181-189

30. Wilson M, Dobson J, Harvey W (1993) Sensitization of Streptococcus sanguis to killing by low power laser light. Lasers Med Sci 8:69-73

31. Bhatti M, MacRobert A, Meghji S, Henderson B, Wilson M (1997) Effect of dosimetric and physiological factors on the lethal photosensitization of Porphyromonas gingivalis in vitro. Photochem Photobiol 65, 1026-1031

32. Soukos NS, Wilson M, Burns T, Speight PM (1996) Photodynamic effects of toluidine blue on human oral keratinocytes and fibroblasts and Streptococcus sanguis evaluated in vitro. Lasers Surg Med 18, 253-259

33. Dobson J, Wilson M (1992) Sensitization of oral bacteria in biofilms to killing by light from a lowpower laser. Arch Oral Biol 37, 883-887

34. Wilson M, Dobson J, Harvey W (1992) Sensitization of oral bacteria to killing by low-power laser radiation. Curr Microbiol 25, 77-81 